should be accompanied by a $0.08^{\circ} \mathrm{C}$ change in global temperature. If so, a 10-ppm $\mathrm{CO}_{2}$ drop requires a global cooling of $0.8^{\circ} \mathrm{C}$. Yet, reconstructed temperature changes for the northern hemisphere (for example, Mann et al., 1999) only permit a cooling of $\sim 0.2^{\circ} \mathrm{C}$ over intervals of many decades to centuries, enough to explain only 2-3 ppm of the 10 ppm $\mathrm{CO}_{2}$ decreases.

Because these $\mathrm{CO}_{2}$ drops are superimposed on a slow background increase attributed to deforestation, I propose that they result from intervals of reforestation tied to human history. Within the large uncertainties of the icecore dating, the three $\mathrm{CO}_{2}$ drops correlate with bubonic plague pandemics that caused enormous levels of human mortality in western Eurasia from 200-600, 1300-1400, and 1500-1720 AD. In addition, major depopulation of native communities across the Americas occurred in the 1500's and 1600's as a result of diseases contracted from initial contact with Europeans. In both cases, historical documents reveal massive abandonment of rural farms and villages after these pandemics.

Trees and shrubs will re-occupy untended farms and sequester atmospheric carbon in amounts equivalent to full reforestation levels within just 50 years, and this mechanism can explain the 10ppm size of the $\mathrm{CO}_{2}$ drops. $\mathrm{CO}_{2}$ decreases caused in this way would then produce a global-mean cooling of $0.15-0.2^{\circ} \mathrm{C}$ (again using the $2.5^{\circ} \mathrm{C}$ IPCC sensitivity estimate), a value that does not violate the hemisphere-wide reconstructions of temperature change. Once the series of plagues abated, the farms were re-occupied, the newly grown forests were cut, and $\mathrm{CO}_{2}$ returned to its long-term rising trend.

The major implications for PAGES are these:

- The underlying long-term climatic trend for the last 8000 years of the Holocene is not natural. Rather than a climate held nearly stable by natural processes, Holocene temperature stability reflects an accidental balance between a large natural cooling and an almost equally large anthropogenic warming.

- During the last 2000 years, shorter-term (decadal- and century-scale) climatic oscillations were not entirely natural. Deforestation episodes, linked to anomalously high human mortality caused by disease, played a significant role in reducing $\mathrm{CO}_{2}$ and cooling climate.

- Distinguishing natural from anthropogenic forcing of Holocene climate will be more difficult than PAGES had thought.

\section{REFERENCES}

Gerber, S., Joos, F., Brugger, P., Stocker, T. F., Mann, M. E., Sitch, S., and Scholze, M., 2003: Constraining temperature variations over the last millennium by comparing simulated and observed atmospheric $\mathrm{CO}_{2}$. Climate Dynamics., 20, 281.

Intergovernmental Report on Climate Change, 2001: Third assessment of the IPCC. Cambridge Univ. Press, Cambridge, UK.

Mann, M.E., Bradley, R.S., and Hughes, M.K., 1999. Northern hemisphere temperatures during the past millennium. Geophysical Res. Lett. 26, 59.

Ruddiman, W.F., 2003: The Anthropogenic Era Began Thousands of Years Ago. Climate Change, 61, 261.

\title{
GLOBEC Investigation of Interdecadal to Multi-Centennial Variability in Marine Fish Populations
}

\section{Tim Baumgartner ${ }^{1}$, Ulrich Struck ${ }^{2}$ and Jürgen Alheit ${ }^{3}$}

'División de Oceanología, CICESE, Ensenada, Baja California, Mexico; tbaumgar@cicese.mx 2Ulrich Struck, GeoBio-Center, München University, Germany; u.struck@Irz.uni-muenchen.de ${ }^{3}$ Baltic Sea Research Institute Warnemünde, Germany; juergen.alheit@io-warnemuende.de

The overarching goal of the Global Ocean Ecosystem Dynamics Project (GLOBEC) of IGBP is to advance our understanding of the structure and functioning of the global ocean ecosystem and its response to physical forcing, and to work towards developing a predictive capability to forecast the regional responses of marine ecosystems to global change. In the past several decades, we have witnessed fundamental changes in the organization and dynamics of large marine ecosystems, which have been manifested in the abundance, diversity and productivity of animal populations, with changes in dominant species. The interaction of climate variability and fishing has also lead to dramatic changes in the abundance and distributions of marine fish populations.

Investigating the nature and cause of these remarkable changes is a formidable challenge because of the need for sampling the ocean over scales of 1000's of square kilometers and for periods of at least several decades. GLOBEC has, therefore, actively encouraged the development of information on ecosystem history contained in the natural, high-resolution archives of marine sediments found in rare locations associated with mid-water oxygen minima in the eastern boundary current regions of the North and South Pacific, and in the South Atlantic, as well as from the glacial fjords located on the poleward edges of these systems in the
Pacific. This information allows us to examine the nature of large-scale variability over a hierarchy of time scales from interannual through interdecadal and centennial. Retrospective research directed toward both paleo- and modern sources, integrated with comparative studies of large ecosystems, provides the historical perspective and framework to describe the underlying natural modes of variability affecting their structure and dynamics. These studies are particularly important for distinguishing the direct effects of human intervention resulting from harvesting or habitat modification, from the natural variability in these systems.

One of the sources of information of particular interest to GLO- 


\section{Science Highlights}

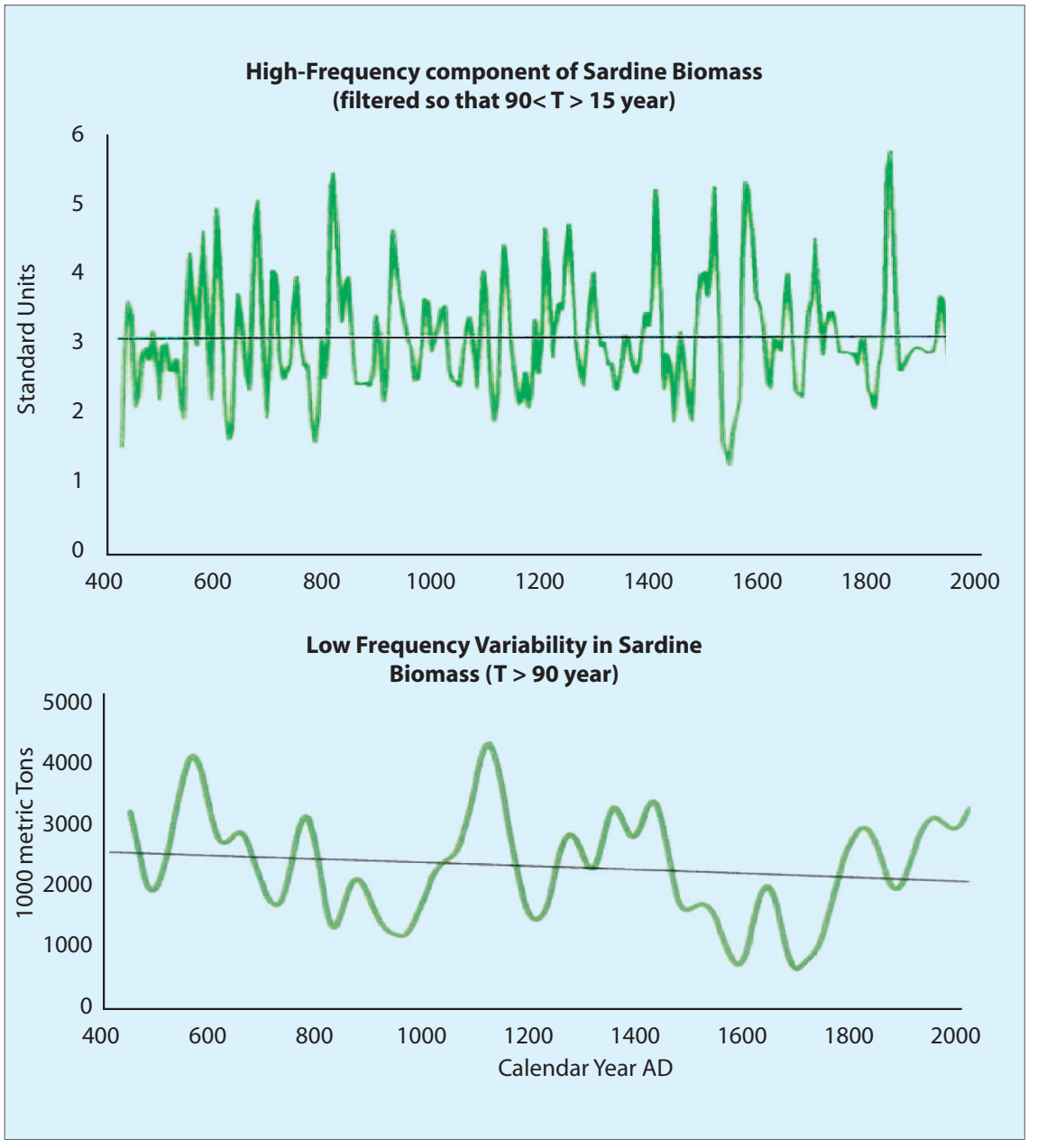

Fig. 1: Biomass of the Pacific sardine population off California reconstructed from 5-year intervals of fish scale deposition in varved sediments of the Santa Barbara Basin: AD 400-1975. The biomass series is partitioned into its high-frequency and low-frequency components.

$B E C$ that has also contributed to the PAGES-PANASH efforts (Markgraf et al., 2000) is the rate of deposition in coastal marine sediments of the scales of small, schooling planktivorous species like sardines and anchovies that form important trophic links in these ecosystems. We believe that these small pelagic fish may be used as bellwether species to infer major changes in the structure of the community. The records of scale-deposition rates allow us to document the modes of variability in abundance (and, where possible, the variability in age structure - from scale sizes) of these populations in the California, the Humboldt and Benguela Current systems, over interdecadal and multi-centennial time scales. We also are striving to develop background environmental information that reflects the regional ocean climate associated with these changes. Depositional sites that provide such detailed histories of ocean populations are rare because of the suite of conditions that must exist - the principal condition being the depletion of oxygen in the overlying bottom water, to enhance the preservation of fish scales and other biological remains and to minimize bioturbation. Under the best circumstances, this combination provides natural calendars of deposition with annual (or near-annual) resolution for the past several thousand years.

Baumgartner et al. (1992) and Holmgren and Baumgartner (1993) demonstrated the value of fish scale records for reconstructing the natural variability of the populations of coastal pelagic fish over time scales of several decades to many centuries. Variability in the abundance of fish scales preserved in coastal marine sediments reflects the rate of scale shedding by live fish, a phenomenon common to the small pelagics that produce rates of scale deposition proportional to local densities of the population. This can be used to hindcast abundance where local density is correlated to overall population size.

The best-developed record of these populations so far is the 1600 -year history of the sardine demonstrated from sediment cores from the Santa Barbara Basin off California. This record is shown partitioned into its high-frequency and low-frequency components in Fig. 1. Variability in these records is a response to basin-scale changes in ocean climate over the Pacific which

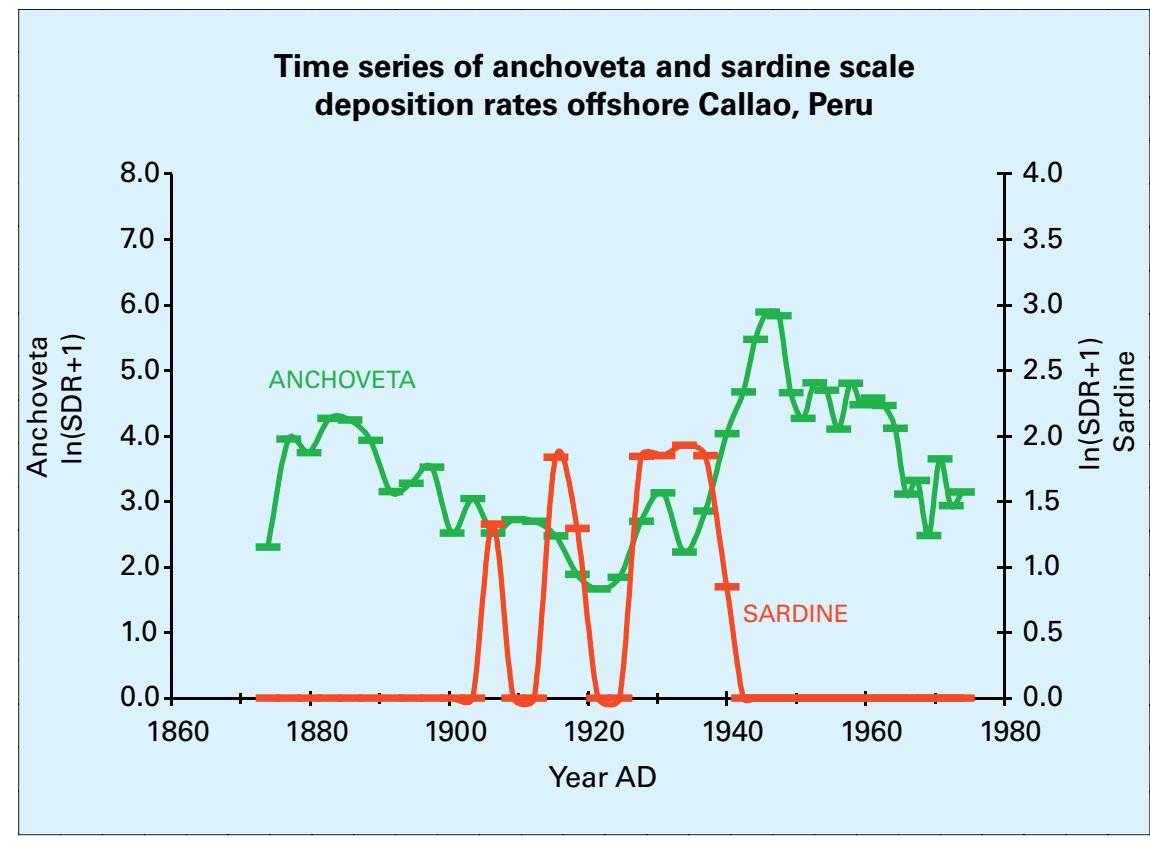

Fig. 2: Time series of anchovy and sardine scale deposition rates (SDR) off Callao, Peru. 


\section{Science Highlights}

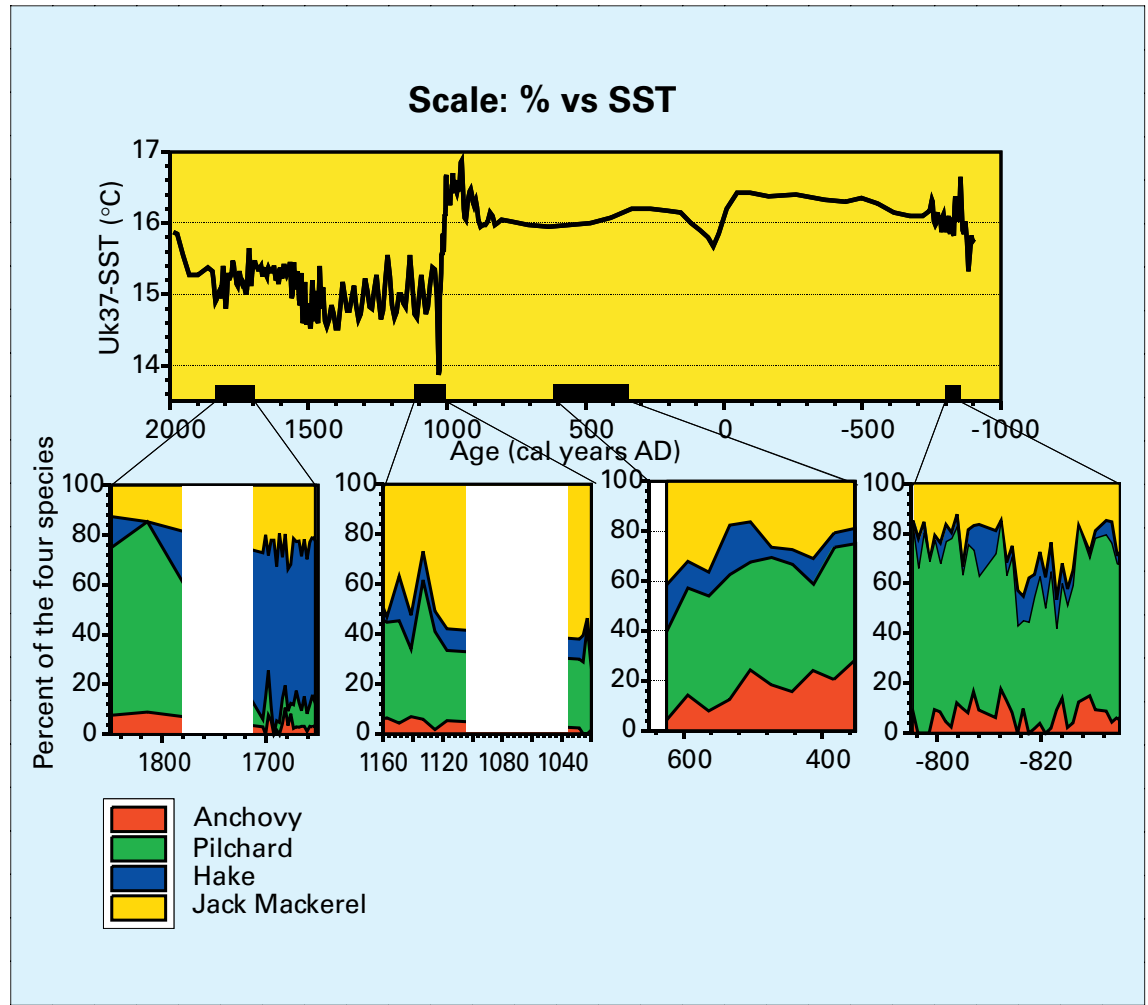

Fig 3: Sea surface temperature (SST) as estimated from the alkenone undersaturation and relative abundance of fish scales from sardine, anchovy, hake and horse mackerel from a sediment core taken in the upwelling area of the Benguela Current off Walvis Bay, Namibia.

results in the latitudinal expansion and contraction of habitat, with associated increases/decreases in abundance of the sardine population. The variance spectra of the high frequency component in Fig. 1 indicate that the expansion and contraction of the sardine habitat of the California Current occurs over a period of around 50 to 60 years. The low-frequency component of sardine biomass in Fig. 1 shows considerable multi-centennial variability, indicating successive warming, cooling and warming of the coastal ocean along North America over the past 1000 years. These changes are correlated with the Medieval Warm Period (950$1350 \mathrm{AD}$ ) and the Little Ice Age (1400-1800 AD) and agree with the detailed record of stable isotopes under development from the Santa Barbara Basin (Field and Baumgartner, 2000). Through the use of the geographically separated sites, it may also be possible to reconstruct not only temporal records of change, but also records of spacetime variability in the populations and the coastal pelagic environment within each current system, using latitudinal comparison of sites through time. Work is now underway to develop north-south comparisons between the Santa Barbara records and a glacial fjord on the west coast of Vancouver Island, British Columbia (500 years of record so far) and with the region off southern Baja California, Mexico (150 years of record so far, Baumgartner et al., 1996).

In the Humboldt Current, our knowledge of very high-resolution records of fish scale-deposition is limited to a couple of sites off Peru that were collected in the 1970s by A. Soutar (Fig. 2). However, this area promises to provide excellent histories of the last several hundred to 1000 years, and renewed efforts at exploration of coring sites are now underway. The relationship between the anchoveta and sardine off Peru shown by Fig. 2 is consistent with the assumption that sardine abundance was relatively high in the Humboldt Current during the 1930's and 1940's although no catch records are available for that period.

In addition to providing highresolution data on fish population dynamics, analysis of varved sediments can provide information on past ocean temperatures and be used to infer changes in ocean circulation and marine species distributions. Sediments also preserve remains of micro-organisms such as diatoms, foraminifera and radiolarians, which are used to reconstruct ancient food webs and productivity changes. Studies on fish scale deposition rates and other proxies in varved sediments off Walvis Bay, Namibia, initiated in the late 1990's, show that sea surface temperature (SST), as estimated from the alkenone undersaturation, varied considerably over the last 1000 years after a relatively steady phase during the preceding 2000 years (Fig. 3). Relative abundances of the major fish populations, determined from fish scale sedimentation records, changed drastically in response to temperature. As in the California Current, fish populations in the Benguela Current exhibited drastic fluctuations long before fisheries existed.

\section{REFERENCES}

Baumgartner, T.R., Soutar, A. and Ferreira-Bartrina, V., 1992: Reconstruction of the history of Pacific sardine and northern anchovy populations over the past two millennia from sediments of the Santa Barbara Basin, California. California Cooperative Oceanic Fisheries Investigations Reports, 33 , 24-40.

Baumgartner, T., Soutar, A. and Riedel, W., 1996 Natural time scales of variability in coastal pelagic fish populations of the California Current over the past 1500 years: Response to global climate change and biological interaction. In. Calif. Sea Grant Rept. for 1992-1995, Calif. Sea Grant College, La Jolla, 31-37

Field, D.B. and Baumgartner, T.R., 2000: A 900-year record of interdecadal and centennial change from the California Current. Paleoceanography, 15 (6), 695-708

Holmgren, D. and Baumgartner, T., 1993: A 250year history of pelagic fish abundance from the anaerobic sediments of the central Gulf of California. California Cooperative Oceanic Fisheries Investigations Reports, 34, 60-68.

Markgraf, V., Baumgartner, T.R., Bradbury, J.P. Diaz, H.F., Dunbar, R.B., Luckman, B., Seltzer, G., Swetnam, T.W. and Villalba, R., 2000: Paleoclimate reconstruction along the Pole-Equator-pole transect of the Americas (PEP 1). Quaternary Science Reviews, 19, 122-140. 